Sáez Pradas, Fernando.

Profesor Sustituto Interino Universidad de Granada. Departamento de Dibujo.

\title{
De Andalucía a California. Un recorrido sobre el imaginario californiano a través del dibujo.
}

\section{From Andalucía to California. A tour of the Californian imagination through drawing.}

\author{
TIPO DE TRABAJO: \\ Comunicación virtual. \\ PALABRAS CLAVE: \\ Dibujo, identidad, política, Nueva Figuración.
}

KEY WORDS:

Drawing, identity, politics, New Figuration.

\section{RESUMEN.}

En el arte, la utopía ha sido y es un concepto transversal que salpica y cruza numerosas disciplinas artísticas. Con la llegada de la post-modernidad, la estética se hizo más relativa y perversa, el fracaso utópico del 68 materializado en el acuerdo entre Charles de Gaulle y los sindicatos marcó un punto de inflexión. Fue entonces cuando muchos artistas decidieron vivir al margen. En España, artistas de la generación de los 70 que vivieron esto muy de cerca dejaron a un lado el pensamiento general de la utopía para ir, poco a poco, centrándose más en un pensamiento utópico del comportamiento humano. Se dejó de creer en lo colectivo para dar paso a lo individual. La verdadera utopía no era más que estar en plena posesión de los sentidos y solo ahí, siendo libre, se podría lanzar un mensaje verdadero. Desde esta perspectiva comenzó -como un juego-, el sueño y la posibilidad de cambio en una sociedad gris. Recordemos que en España, aunque el dictador estuviese cerca de ser un residuo, su ideología estaba aun profundamente tatuada en la sociedad. Se necesitaba un nuevo escenario, en una España podrida, toda una generación de artistas pensó en California como el edén. Era una situación que rozaba el absurdo pues ninguno de los artistas de los 70 había estado allí. California era el paraíso anhelado, la igualdad entre diferentes estratos sociales, el trópico, un lugar de ambiente cálido y libertino que supondría un soplo de aire fresco para la generación que tenía la responsabilidad -consciente o inconsciente- de promover el cambio en el panorama cultural español. Un aire que lograron introducir en la pintura española, reivindicando el derecho a imaginar oprimido tras la losa negra de una dictadura de derechas y fuerte raíz católica.

\section{ABSTRACT.}

In art, utopia has been and is a cross-cutting concept that crosses and crosses artistic disciplines. With the advent of postmodernity, aesthetics became more relative and perverse, the utopian failure of the 68 embodied in the agreement between Charles de Gaulle and the unions marked a turning point. It was then that many artists decided to live on the sidelines. In Spain, artists of the generation of the 70 who lived this very closely put aside the general thought of utopia to go, little by little, focusing more on a utopian thinking of human behavior. He let himself be believed in the collective to make way for the individual. The true utopia was nothing more than to be in full possession of the senses and only in being free could a true message be sent. From this perspective started - as a game - the dream and the possibility of change in a gray society. Recall that in Spain, although the dictator was close to being a residue, his ideology was still deeply tattooed in society. A new stage was needed, in a rotten Spain, an entire generation of artists thought of California as Eden. It was a situation that was absurd because none of the artists of the 70 had been there. California was the longed for paradise, the 
equality between different social strata, the tropics, a place of warm and libertine atmosphere that would suppose a breath of fresh air for the generation that had the responsibility - conscious or unconscious - to promote the change in the cultural panorama An air that introduces in the Spanish painting, claiming the right to an imaginary oppressed after the black stone of a dictatorship of right and strong Catholic root.

\section{CONTENIDO.}

\section{INTRODUCCIÓN.}

Utopía, hermoso concepto apenas alcanzable. Hoy más que nunca esta idea sobrevuela el imaginario de todos. Inmersos en una crisis económica sin parangón, consecuencia probablemente, de una crisis de valores, la posibilidad de soñar con un mundo libre, mejor y justo es cada vez más necesaria.

No hay duda del poder comunicativo y transformador que tiene la imagen, convertida en un lugar estético, de enorme calado y a través de la cual podemos posicionarnos y/o desarrollar una posición ética y política ante las conductas sociales.

A lo largo de estos años oscuros, será difícil eliminar de nuestro subconsciente la imagen de las personas que vimos desalojadas de sus hogares, aquellos que se quemaron a lo bonzo en la puerta de algún banco, o imborrable -hasta el siguiente anuncio publicitariopermanecerá aquella cruda imagen de Aylan, el pequeño niño sirio ahogado en una playa turca. Todo esto quedará almacenado en nuestra memoria a través del material que los medios de comunicación han ido publicando. Una dura, durísima, dosis de realidad administrada en imágenes. Ante ello, la posibilidad de dar una respuesta utópica será vital para soportarla.

En el arte, la utopía ha sido y es un concepto transversal que salpica y cruza numerosas disciplinas artísticas. Por supuesto, la fotografía es una de las más evidentes y poderosas, aún recordamos la reproducción de Marc Riboud cuando con una simple margarita desafió a un ejército en plena Guerra de Vietnam. $O$ aquellas acciones y grafitis que iban apareciendo paulatinamente en París durante el mayo del 68. La ciudad se inundaba de mensajes directos, contundentes y breves, como si de tweets se trataran, que nos animaban con pasión a darle una vuelta al mundo. El mundo hippy, por qué no decirlo, con una gran carga de ingenuidad, fue un revulsivo de ilusión que ayudó a pensar que realmente era posible apostar por un cambio en el sistema. La utopía de los 60 fue la medicina para un mundo que había enfermado tras la II Guerra Mundial.

No solo fue la fotografía la que nos conectaba con la nueva imaginación, otras disciplinas, como el Land art, la arquitectura, instalaciones, la pintura o el dibujo también facilitaron la conexión con el ansiado espejismo aunque poco a poco, esa utopía se fue convirtiendo en frivolidad ante la imposibilidad de materializarse. Con la llegada de la post-modernidad, la estética fue mucho más relativa y perversa, el fracaso utópico del 68 con el acuerdo entre Charles de Gaulle y los sindicatos marcó un punto de inflexión, trayendo consigo una transformación del pensamiento para una nueva generación de artistas. Un punto éste especialmente importante, pues fue entonces cuando muchos decidieron vivir al margen -en la medida de lo posible- de servidumbres hacia la política y a lo que el significado de la palabra institución soportaba.

Artistas de la generación de los 70 que vivieron esto muy de cerca dejaron a un lado el pensamiento general de la utopía para ir, poco a poco, centrándose más en un pensamiento utópico del comportamiento humano. Se dejó de creer en lo colectivo para dar paso a lo individual. La verdadera utopía no era más que estar en plena posesión de los sentidos y solo ahí, siendo libre, se podría lanzar un mensaje verdadero.

Desde esta perspectiva comenzó, como un juego, el sueño y la posibilidad de cambio en una sociedad gris. Recordemos que en España, aunque el dictador estuviese cerca de ser un residuo su ideología estaba aun profundamente tatuada en la sociedad y cualquier cosa que se apartara de la norma acababa siendo un desafío al orden moral y político que se había instaurado.

Se necesitaba un nuevo escenario, en una España podrida, toda una generación de artistas pensó en California como el edén. Era una situación que rozaba el absurdo pues ninguno de los artistas de los 70 había estado allí. California era el paraíso anhelado, la igualdad entre diferentes estratos sociales, el trópico, un lugar de ambiente cálido y libertino que supondría un soplo de aire fresco para la generación que tenía la responsabilidad-consciente o inconsciente- de promover el cambio en el panorama cultural español. Un aire que lograron introducir en la pintura española, reivindicando el derecho a imaginar oprimido tras la losa negra de una dictadura de derechas y fuerte raíz católica. 


\section{DESARROLLO.}

Mientras las producciones de Hollywood palpitaban a través del torrente sanguíneo de la región, a mediados de los 60 Los Angeles se convertía en la ciudad rock más importante de EEUU. David Hockney estaba desarrollando su gusto brillante por el arte pop y su concepto de pintura al aire libre, mientras Philip Guston, el más tranquilo y suave de los expresionistas americanos, también se formaba allí. La cultura del automóvil empezaba a gestarse y dominar las vastas carreteras que tanto marcarán la obra de Ruscha quien, a través de una fotografía de mirada inexpresiva, capta estaciones de servicios, gasolineras y carreteras desérticas. El optimismo tecnológico de los años 60 pasa a formar parte del Sueño Californiano, que se encuentra presente en casi todos los hogares. Y si no es así se aspira a conseguirlo: máquinas de Coca-cola, césped, piscinas, mesas de picnic, barbacoas para todos y coches por doquier se asientan en el imaginario colectivo como el American Way of Life (Whiting, 2006)

La subcultura del automóvil será una de las señas de identidad que lo inunden todo, incluido el arte. Vemos a Judy Chicago como ejemplo de artista californiana. Ella usó como soporte para sus trabajos el capó del legendario Chevrolet Corvair de los años 60, produciendo pinturas brillantes y metalizadas. O el caso de James Rosenquist y su célebre obra I love you with my Ford (1961). Aquí nos presenta uno de esos ejemplos de cómo la sociedad ha cambiado sus referentes, no solo iconográficos, sino también conceptuales. Ahora actividades dedicadas al tiempo libre u ocio, como puede ser el cine o pasear en coche y comprar comida rápida en una gasolinera, serán elementos distintivos de un colectivo en plena transformación, de una sociedad que emerge del oscurantismo del expresionismo abstracto a la cultura pop.

Entre las décadas de los 50 y 60, California florece culturalmente, eliminando complejos de inferioridad con respecto a otros estados, si tenemos en cuenta que Los Ángeles era considerada como tierra vulgar llena de filisteos. En este momento, en torno al West Hollywood's, donde ahora se ubica la legendaria Ferus Gallery, se congrega un grupo de jóvenes entre los que destacó Ed Ruscha. Las películas estaban en Los Ángeles, las autopistas, la playa, el desierto... todo tenía un ritmo acelerado aunque carecía de la profundidad cultural de Nueva York (Bradnock, y otros, 2011). Estar alejado del foco neoyorquino que parecía absorberlo todo, permitía a los artistas de Los Ángeles establecer otras relaciones ${ }^{1}$. Aquí no tenían la presión de las ventas del mercado, y la gran cantidad de espacio disponible les permitía tener estudios amplios a costos más reducidos. Muchos de los artistas ni siquiera vendían obras y si lo hacían era algo que ocurría fortuitamente, muy de tarde en tarde. A veces pintaban solo para compartir los cuadros con sus compañeros pintores, lo que les llevaba a ganarse la vida -en términos económicos- con profesiones paralelas como la enseñanza (Karlstrom, 2001). En Los Ángeles era mucho más fácil experimentar que en el epicentro de la escena artística de Nueva York o París, allí un artista corría menos riesgos, y por eso, también era más libre (Peabody, y otros, 2011).

La percepción de California y en concreto de Los Angeles como el edén, fue acentuándose cada vez más, captando poco a poco la atención de muchos, que la idealizaban como un paraíso moderno, seduciéndolos y al que acudieron casi cegados como por cantos de sirena. Tras las riquezas del oro y el desarrollo de la industria del cine, Los Ángeles fue -y sigue siendo- un lugar excesivo en muchos aspectos sociales y económicos, pero también en lo que a sus características geográficas se refiere. Allí confluyen los cuatro elementos naturales: tierra (vastas extensiones y desiertos), aire y luz (muy densos), fuego (todos los veranos hay incendios en las colinas), y el agua (representada a través de sus piscinas y la fiebre del surf). Estos poderosos rasgos climatológicos y geográficos atraparon a los artistas de California, que fueron recorriendo en diferentes formas y grados -en lo que al compromiso de implicación se refiere- estos cuatro elementos. Los artistas empezaron a experimentar con nuevos materiales intentando traducir lo más inmediatamente posible el poder de esa tierra, y así lo intentó Peter Alexander, un artista que comenzó a usar unas resinas tremendamente luminosas en sus esculturas. Poco a poco se empieza a desarrollar un arte con connotaciones autóctonas, alejado de los estereotipos del pop de la costa este.

\section{CONCLUSIONES.}

Desde España, artistas de toda una generación, como Luis Gordillo, Chema Cobo, Carlos Franco, Guillermo Pérez Villalta, Manolo Quejido y varios más, habían fijado California como el lugar mental donde todas sus experimentaciones ocurrirían. Había un elemento que conectaba la tierra americana con Andalucía. Nos referimos a la Palmera, este icono del trópico que aparecía en ambos lugares y que les hizo ver a California como un lugar familiar. Todos experimentaron con este elemento de un modo u otro. Por otro lado, la visión que tanto Hockney como Ruscha estaban trasladando al mundo sobre las piscinas y que tímidamente llegaba a España, también fue un revulsivo para los artistas españoles. Todos vieron en lo líquido un elemento a explorar, en pleno apogeo de las teorías de Bauman, todo cobraba más sentido.

Cada uno trabajó desde su prisma personal y hubo factores que serían determinantes de todo el trabajo. Uno de los catalizadores más importantes que coexistió en torno a toda la generación fue el humor. Éste fue inundando todo el trabajo que iban haciendo, especulando con California, con lo que sería aquella tierra en la que nunca habían estado. "Por un lado en aquel momento lo hippie

\footnotetext{
1 "Decían los neoyorquinos que éramos más lentos, que no nos movíamos a su ritmo" comentaba la artista Nacncy Buchanan en el documental Pacific Standard Time, señalando que no era una connotación negativa para ella.
} 
hacía mucho y California era California Dream. Nos sonaba a libertad. Allí estaban las libertades sexuales y de todo género. Y por otro lado estaba el lado hollywoodiense, el mundo de las piscinas que nos llegaba un poco también a través de Hockney y todos estos artistas. Y luego después, hubo otra historia. Yo hice una serie que se llamaba Homenaje a la Costa del Sol, que se expuso primero en la Galería Vandrés y después aquí en el Monasterio de la Cartuja hace unos años. Recuerdo que a la casa que tenía en aquel entonces Bola Barrionuevo le pusimos de nombre California. Se lo puso creo Herminio Molero. Y entonces había un paisaje, que era un paseo marítimo visto desde la casa de Bola y al que yo titulé "paisaje visto desde California" y la gente lo interpretó como que yo estaba viendo el paisaje andaluz a través de la idea de California. En cierta medida sí era así, era como encontrar a través de la imagen de la Costa del Sol, la idea de la California imaginada, la ideal. Yo siempre he homenajeado mucho a la Costa del Sol, porque para mí siempre ha sido muy importante. Nací en Tarifa, donde viví gran parte de mi vida, y luego también he vivido en Málaga de donde era la familia de mi padre. Yo he estado paseando por la Costa del Sol desde finales de los años cuarenta hasta ahora y he visto toda su evolución, además desde niño siempre me he fijado mucho en la arquitectura, cosa que la mayoría de los niños no se fijan, pero que yo sí hacía. Con cinco o seis años yo recuero que me llamaba profundamente la atención la arquitectura. Y yo he visto toda esa evolución de la Costa del Sol que tenía que ver mucho con California." (Guillermo Pérez Villalta y la Nueva Figuración Madrileña, 2013).

En cuanto a la palmera, cuenta Villalta lo importante que ha sido para él durante toda su vida. Ser de Tarifa hizo que desde su nacimiento estuviera rodeado de ellas. El humor y la iconografía se entremezclaban hasta el histrionísmo llegando al punto de "sortear" el nombre que iba a ponérsele a la hija de Javier Utray -personaje muy importante para toda la Nueva Figuración Madrileña. Los nombres resultantes fueron Palmera o Palmira y como el segundo sonaba más convencional se optó finalmente por el segundo. Para ellos era un símbolo estético que no provenía del norte, y que se conectaba directamente con la cultura mediterránea. (Guillermo Pérez Villalta y la Nueva Figuración Madrileña, 2013). Tanto la palmera como la piscina se conectaban con Caifornia y con Andalucía permitiendo así el viaje soñado que les permitía huir de la España apagada por la dictadura franquista.

\section{FUENTES REFERENCIALES.}

Bradnock, Lucy y Singh, Rani. 2011. Papa's Got a Brand New Bag. Crafting and Art Scene. [ed.] Rebecca Peabody, Andrew, Phillips, Glenn Perchuk y Rani Singh. Pacific Standard Time. Los Agneles Art 1945-1980. Los Angeles : Getty Research Institute y J. Paul Getty Museum, 2011, 2, págs. 67-124.

Guillermo Pérez Villalta y la Nueva Figuración Madrileña. Sáez Pradas, Fernando. 2013. s.l. : Asociación Aragonesa Críticos de Arte, 2013, AACA Digital. , Vol. 23, págs. 1-14.

Karlstrom, Paul J. 2001. Art School Sketches: Notes on the Central Role of Schools in California Art and Culture. [aut. libro] Stephanie Barron, y otros. [ed.] Stephanie Barron, Sheri Bernstein y llene Susan Fort. Reading California. Art, Image, and Identity, 1900-2000. Los Angeles : Los Angeles County Museum of Art y University of California Press, Berkeley, Los Angeles y London, 2001, págs. 85-109. Peabody, Rebecca, y otros. 2011. Shifting the Standard. Reappraising Art in Los Angeles. Pacific Standard Time. Los Angeles Art 19451980. Los Angeles : Getty Research Institute y J.Paul Getty Museum, 2011, págs. 1-3.

Whiting, Cécile. 2006. Pop L.A. Art and the City in the 1960s. California : University of California Press, Berkeley and Los Angeles, 2006. 